\title{
Phenotypic analysis of Arabidopsis thaliana arginine-deficient mutants
}

\author{
Shahbaz Anwar ${ }^{1,2 *}$, Muhammad Amjad Ali $^{1}$, Erich Inselsbacher ${ }^{3}$ and \\ Krzysztof Wieczorek ${ }^{1}$ \\ 1. Institute of Plant Protection, Department of Crop Sciences, University of Natural Resources and Life Sciences, \\ Konrad Lorenz-Strasse 24, 3430 Tulln, Austria \\ 2. Botany Department, Government Postgraduate College, Sahiwal, Pakistan \\ 3. Department of Geography and Regional Research, University of Vienna, 1010 Vienna, Austria \\ *Corresponding author's email: shahbazanwarch@hotmail.com
}

Citation

Shahbaz Anwar, Muhammad Amjad Ali, Erich Inselsbacher and Krzysztof Wieczorek. Phenotypic analysis of Arabidopsis thaliana arginine-deficient mutants. Pure and Applied Biology. Vol. 11, Issue 1, pp302-314. http://dx.doi.org/10.19045/bspab.2022.110032

\begin{tabular}{llll}
\hline \hline Received: 05/04/2021 & Revised: 19/06/2021 & Accepted: 27/06/2021 & Online First: 12/07/2021 \\
\hline \hline
\end{tabular}

\section{Abstract}

Arabidopsis thaliana has been successfully used as a model organism for agriculture research. This model plant gives the opportunity to find out novel ways for the manipulation of gene function to improve commercial crop production. To elucidate gene function, reverse genetics got ample attention. Reduced gene expression in model plant and its implications as phenotypic response aids large scale investigation of gene functions. To find out the effect of the reduced arginine content on plant growth and development, we did a complete phenotypic analysis of arginine-deficient mutants. We generated artificial microRNA (amiRNA)-based mutants for two genes in arginine biosynthesis, argininosuccinate synthase $(A S)$ and argininosuccinate lyase $(A L)$. Quantitative real time PCR (qRT-PCR) of mutant plants showed reduced gene expression. In case of $A S$ mutant lines, as 3-3 and as2-6 showed almost 60\% decrease in gene expression. Whereas two $A L$ mutants all-5 and al4-3 showed more than 50\% decrease in gene expression. Amino acid analyses of mutant plant lines by Ultra High-Performance Liquid Chromatography (UPLC ${ }^{\mathrm{TM}}$ ) showed reduced arginine production as compared to wild type plants. Arginine content of 20-day-old as2-6 and al4-3 lines was reduced to $46 \%$ and 54\%, respectively. However, in 30-day-old plants arginine levels tend to increase and in as2-6 and al4-3 lines the arginine content was 50\% and 57\% respectively, finally, the phenotypic analysis revealed altered rosette growth and delayed flowering response in mutant plants as compared to the wild type plants. Our results provide insights on the role of arginine metabolism in plant rosette growth and initiation of flowering.

Keywords: Arabidopsis thaliana; Arginine-deficient mutants; Argininosuccinate synthase; Argininosuccinate lyase; Phenotypic analysis; Quantitative RT-PCR

Introduction

Arabidopsis thaliana is a small flowering plant from the mustard family having several traits that made it the first choice as a model plant, especially for genetic and metabolomics studies [1, 2]. A. thaliana genome project identified nearly all its genes and their corresponding sequences [1]. However, insights into function of these genes remain still widely unexplored. To 
cope with this deficiency, the reverse genetics is used as a suitable genetic engineering tool to find out the gene function and to explore complex interactions among thousands of genes $[3,4]$. To achieve this, gene disruption, also known as gene knockout or gene silencing i.e., reduction of gene expression, is widely used technique. In most cases, dominant null mutation may appear lethal and such plants will not survive and instead of gene knockout, reduction in gene function using the RNA interference (RNAi) becomes the tool of choice. In this technique, expression of a gene is reduced by antisense RNAs [5]. Post-Transcriptional Gene Silencing is a biological response against double stranded RNA to incur resistance against viruses and to regulate gene expression. Plant microRNAs (miRNAs) can target RNA molecules highly complementary to them. Due to this reason, artificial microRNA (amiRNA) becomes a tool of choice for the reduction of gene expression in plants [6]. Finally, to completely understand the effects of gene knockout or gene silencing and following disruption of its function, the resulting phenotype must be properly identified. However, search for a phenotype clearly distinct from wild type could be a tedious process due to several factors such as gene redundancy, very minute changes in growth and development and natural variability of plants [7].

Plant growth and development is mostly limited by nutrient availability. Nitrogen is a limiting nutrient in most of the cases and thus its metabolism is getting considerable attention in plant research. Amino acid arginine serves as a precursor for many important molecules associated with cellsignaling, polyamine and nitric oxide (NO) production [8] being an important metabolite for several cellular processes. Arginine is an important storage and nitrogen-transport molecule in plants [9]. In plants, it is produced from ornithine, which is catabolized to citrulline by Ornithine transcarbamylase (OTC). Subsequently, argininosuccinate synthase (AS) synthesizes argininosuccinate from citrulline. Finally, argininosuccinate lyase (AL) produces arginine from argininosuccinate $[10,11]$. Arginine forms $40-50 \%$ of total nitrogen reserve in seed proteins [12] and is an important storage form of nitrogen in roots and underground organs of plants [13]. Arginine metabolism has a significant role in nitrogen recycling and distribution in plants [11] and is also used to fine-tune many developmental responses during plant growth and development as well as during plant biotic stress $[10,14]$. In this study, we determined phenotypic implications of arginine deficiency during the entire growth and development of $A$. thaliana. We focused on the phenotypic interpretation of differences between wild type and mutant lines resulting from the genetic variation induced by targeted gene silencing of arginine metabolic pathway.

\section{Materials and Methods}

\section{Plant growth conditions}

Surface-sterilized seeds of A. thaliana wild type (Col-0) and the mutant lines (as3-3, as2-6, al1-5 and al4-3) were grown on half strength MS medium [15] without supplemented sucrose in the plate-based experiment. For soil-based analysis, seeds were grown in pots. Growth conditions for both plate- and soil-based experiments were $16 \mathrm{~h}$ light $/ 8 \mathrm{~h}$ dark and $25^{\circ} \mathrm{C}$.

\section{Gene silencing by artificial microRNAs}

Artificial microRNA (amiRNA) was generated into the endogenous A. thaliana miR319a precursor by site-directed mutagenesis [6]. Briefly sequence of amiRNAs for both $A S$ (At4G24830) and $A L$ (At5G10920) genes were identified by using the "WMD Web Micro-RNA Designer" (http://wmd2.weigelworld.org). Online tool generated sequence for four oligonucleotides 
(I to IV) are presented in Table 1. These oligonucleotides were used as primers in a PCR-based amplification of miR319a template to generate amiRNA sequences. Obtained amiRNA sequences were inserted into the modified pPZP3425 vector [16] already heaving kanamycin resistance gene and double 35S CaMV promoter. Resulting plasmids were sequenced to confirm the presence of inserts. A. thaliana wild type
(Col-0) plants were transformed with these plasmids using the floral dip technique [17]. Seeds were collected from transformed plants and screened on $50 \mathrm{mg} / \mathrm{l}$ kanamycin containing medium. Homozygous plants were collected after segregation analysis of the selected seeds. Gene silencing efficiency of the amiRNA was tested by qRT-PCR using primers shown in the (Table 1).

Table 1. Primers used for amiRNA cloning and qRT-PCR

\begin{tabular}{|c|c|r|}
\hline Gene & Direction & Primer Sequence 5'- 3' \\
\hline \multirow{2}{*}{$\begin{array}{c}\text { At4G24830 } \\
(A S)\end{array}$} & I & GATTAAAGACGAATAAACCCGGGTCTCTCTTTTGTATTCC \\
\cline { 2 - 3 } amiRNA & II & GACCCGGGTTTATTCGTCTTTAATCAAAGAGAATCAATGA \\
\cline { 2 - 3 } & III & GACCAGGGTTTATTCCTCTTTATTCACAGGTCGTGATATG \\
\cline { 2 - 3 } & IV & GAATAAAGAGGAATAAACCCTGGTCTACATATATATTCCT \\
\cline { 2 - 3 } At5G10920 & I & GATTCTACAAAAGTTAAGAGGACTCTCTCTTTTGTATTCC \\
\cline { 2 - 3 }$(A L)$ amiRNA & III & GAGTCCTCTTAACTTTTGTAGAATCAAAGAGAATCAATGA \\
\cline { 2 - 3 } & IV & GAGTACTCTTAACTTATGTAGATTCACAGGTCGTGATATG \\
\hline At4G24830 & Forward & AAAAGCACGGGATTGGGCGGA \\
\cline { 2 - 3 }$(A S)$ qRT-PCR & Reverse & GCGGATCAAACCATCTTCCTGCG \\
\hline At2G10920 & Forward & GCAGCTCGAACGTGATGCTGGT \\
\cline { 2 - 3 }$(A L)$ qRT-PCR & Reverse & CCTCGGAAGCCCACAGTACCCA \\
\hline 18S rRNA & Forward & TGACACGGGGAGGTAGTGACA \\
\cline { 2 - 3 } qRT-PCR & Reverse & AGTCTGGTAATTGGAATGAGTACAATCTAA \\
\hline
\end{tabular}

\section{Sample collection, RNA extraction and quantitative RT-PCR}

Samples were collected from A. thaliana wild type (Col-0) and mutant lines (as3-3, as 2-6, all-5 and al4-3). Samples were immediately frozen in liquid nitrogen. Total RNA was extracted using the RNeasy Plant Mini Kit (Qiagen, Hilden, Germany), manufacturers provided extraction protocol was used, which included a DNase I digestion step to remove any DNA contamination (Qiagen, Hilden, Germany). Total RNA was analyzed for quality and quantity by using Agilent 2100 bioanalyzer (Agilent Technologies, Palo Alto, CA, USA). Random primers [oligo(dN)6] and the SuperScript III reverse transcriptase (Invitrogen, Carlsbad, CA, USA) was used to transcribe cDNA from total RNA according to the producer's provided protocol. Quantitative real-time PCR was performed using ABI PRISM 7300 Sequence Detector PCR machine (Applied BioSystems). PCR program was carried out at $50^{\circ} \mathrm{C}$ for $2 \mathrm{~min} 95^{\circ} \mathrm{C}$ for $5 \mathrm{~min}$ followed by 40 cycles at $95^{\circ} \mathrm{C}$ for $15 \mathrm{~s}, 60^{\circ} \mathrm{C}$ for $30 \mathrm{~s}$ and $72^{\circ} \mathrm{C}$ for $1 \mathrm{~min} .18 \mathrm{~S}$ rRNA primers were used as internal reference. Sequences of all primers for qPCR are given in Table 1. Data analysis was performed by Sequence Detection Software SDS v2.0 (Applied BioSystems, USA). Three independent biological replicates from each plant line were used for RNA extraction. Each replicate was run in three technical replicates to minimize the experimental errors. Relative gene expression was calculated using $2^{-\Delta \Delta \mathrm{CT}}$ method [18]. 


\section{Amino acid analysis}

Plants were harvested from culture plates at 20 and 30 days after germination. Sampling was done for five biological replicates from independently grown plants. Plant material was frozen in liquid nitrogen and homogenized with a mixer mill at maximum frequency for $1 \mathrm{~min}$ in $1.5 \mathrm{ml}$ Eppendorf tubes. Extraction was done using a solvent mix containing $20 \%$ (v/v) chloroform, $20 \%$ $(\mathrm{v} / \mathrm{v})$ distilled water and $60 \%(\mathrm{v} / \mathrm{v})$ methanol. Samples were centrifuged for 10 $\min$ at $14000 \mathrm{rpm}$. Supernatant was transferred into clean sterilized tubes. Aqueous phase was evaporated with a speed-vac (Savant Speedvac SPD 111; Thermo Fisher Scientific Inc., Waltham, MA, USA). Reversed-phase liquid chromatography using a Waters Ultra HighPerformance liquid chromatography (UPLC $^{\mathrm{TM}}$ ) system with a Waters Tunable UV (TUV) detector was performed for quantification of amino acids in each sample as described previously [19].

\section{Phenotypic analysis}

Homozygous lines selected on kanamycin were subjected to growth stage-based phenotypic analysis to check if mutation is associated with a specific phenotype. Phenotype analysis was performed for the growth stages described previously $[20,21]$. Experiment was divided into two phases.

In first phase (plate-based experiment) analysis was done on sterile culture media. Surface-sterilized seeds of A. thaliana wild type (Col-0) and mutant lines (as3-3, as2-6, all-5 and al4-3) were sown on Petri plates containing $40 \mathrm{~mL}$ of sterile $0.5 \mathrm{x}$ MS medium [15] without supplemented sucrose. Plates were incubated in a cold room for 3 days at $4^{\circ} \mathrm{C}$ to synchronize germination and then transferred to growth chamber at $16 \mathrm{~h}$ light $/ 8 \mathrm{~h}$ dark and $25^{\circ} \mathrm{C}$. Daily measurements were performed to assess seedling development from the first day in the growth chamber until the growth stage 1.05 is attained in $50 \%$ of the plants. Plates were placed in a randomized block design and shuffled after every measurement cycle. Five biological replicates were used for each plant line. Growth stages studied during this phase are listed in (Table 2; Fig. 1).

In the second phase (soil-based experiment) plants were grown in individual $3 \times 3$ inch pots with a standard potting compost mixture. Pots were placed in plastic trays (in a $3 \times 5$ grid manner). Trays were placed in growth chamber at $16 \mathrm{~h}$ light $/ 8 \mathrm{~h}$ dark and $25^{\circ} \mathrm{C}$ after three days of stratification at $4^{\circ} \mathrm{C}$. Plants were watered by sub-irrigation in trays when needed. Growth stages were recorded as described in (Table 3; Fig. 1). Five biological replicates were used for each plant line. Pots in each trial were shuffled after every measurement cycle.

\section{Statistical analysis of the data}

Statistical variations among the wild type and mutant plants were tested using ANOVA and LSD tests ( $p<0.05)$. Data of qRT-PCR was analyzed by using Students ttest. Software package STATGRAPHICS Plus Version 5.0 was used for statistical analysis of the data.

Table 2. Growth stages defined for Arabidopsis thaliana for phenotypic analysis on MS media in culture plates $[20,21]$

\begin{tabular}{|c|c|c|c|}
\hline \multicolumn{2}{|c|}{ Seed Germination Analysis } & \multicolumn{2}{c|}{ Development of Rosette Leaves } \\
\hline 0.10 & Imbibition of seed & 1.0 & Cotyledons opened \\
\hline 0.50 & Emergence of radicle & 1.02 & Two rosette leaves $\geq 1 \mathrm{~mm}$ \\
\hline 0.7 & Hypocotyl and cotyledon appearance & 1.04 & Four rosette leaves $\geq 1 \mathrm{~mm}$ \\
\hline & & 1.05 & $\begin{array}{c}\text { Primary roots } \geq 3 \mathrm{~cm} \text { in length in } \geq 50 \% \text { of the } \\
\text { seedlings }\end{array}$ \\
\hline
\end{tabular}




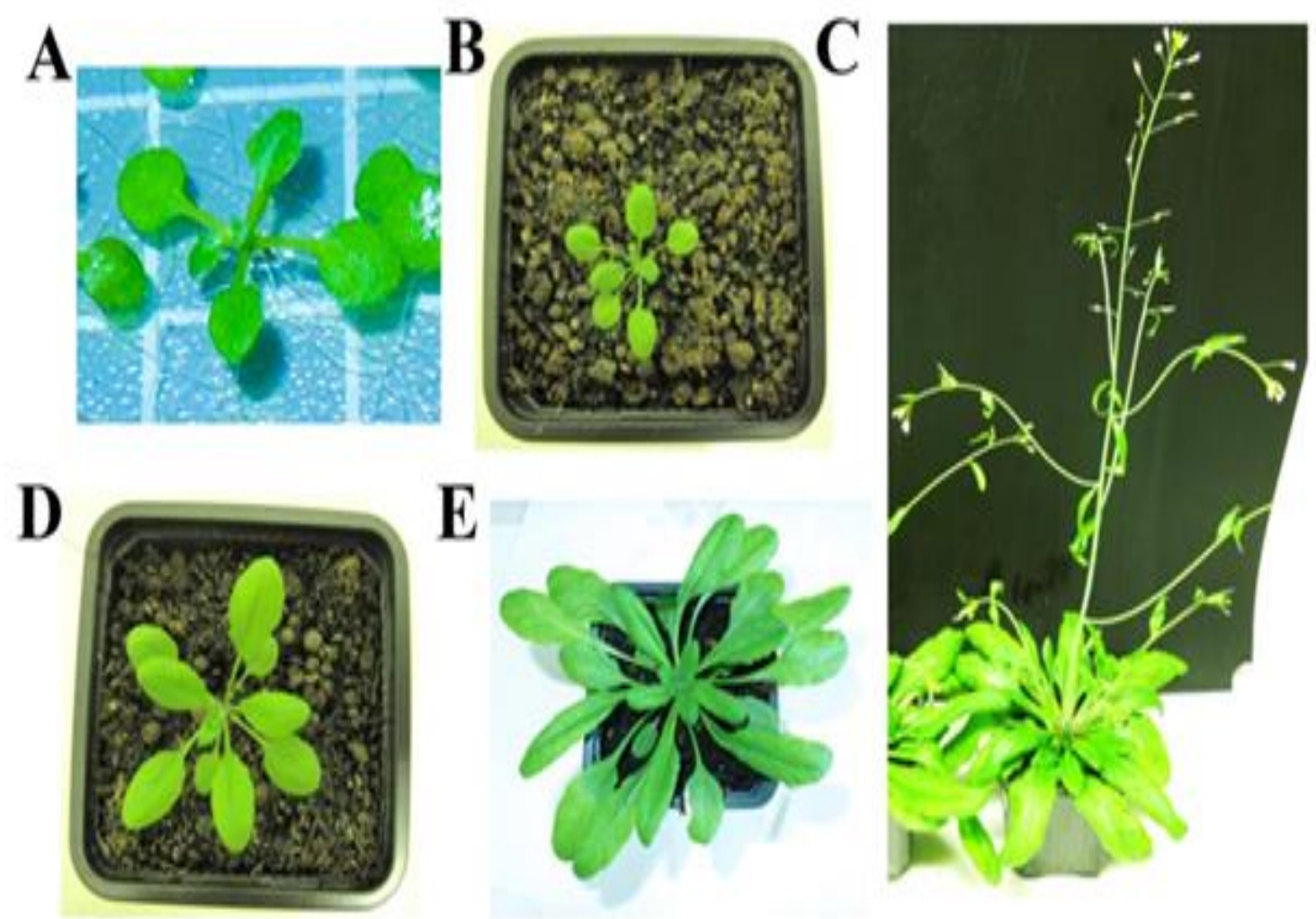

Figure 1. Growth stages defined for Arabidopsis thaliana. (A) 1.04; Four rosette leaves $\geq 1$ mm. (B) 1.08; Eight rosette leaves $\geq 1 \mathrm{~mm}$. (C) 6.50; Flower blooming $\geq 50 \%$. (D) 1.10; Ten rosette leaves $\geq 1 \mathrm{~mm}$. (E) 5.10; First flower bud appears

Table 3. Growth stages defined for Arabidopsis thaliana for phenotypic analysis on compost mixture in pots $[20,21]$

\begin{tabular}{|c|c|c|c|}
\hline \multicolumn{2}{|r|}{ Development of Leaves } & \multicolumn{2}{|r|}{ Development of Rosette Leaves } \\
\hline 1.02 & Two rosette leaves $\geq 1 \mathrm{~mm}$ & 3.20 & Rosette $\geq 20 \%$ of full size \\
\hline 1.03 & Three rosette leaves $\geq 1 \mathrm{~mm}$ & 3.50 & Rosette $\geq 50 \%$ of full size \\
\hline 1.04 & Four rosette leaves $\geq 1 \mathrm{~mm}$ & 3.70 & Rosette $\geq 70 \%$ of full size \\
\hline 1.05 & Five rosette leaves $\geq 1 \mathrm{~mm}$ & 3.90 & Rosette $\geq 100 \%$ of full size \\
\hline 1.06 & Six rosette leaves $\geq 1 \mathrm{~mm}$ & \multicolumn{2}{|r|}{ Emergence of Inflorescence } \\
\hline 1.07 & Seven rosette leaves $\geq 1 \mathrm{~mm}$ & 5.10 & First flower bud appears \\
\hline 1.08 & Eight rosette leaves $\geq 1 \mathrm{~mm}$ & \multicolumn{2}{|r|}{ Production of Flowers } \\
\hline 1.09 & Nine rosette leaves $\geq 1 \mathrm{~mm}$ & 6.00 & First flower bloom \\
\hline 1.10 & Ten rosette leaves $\geq 1 \mathrm{~mm}$ & 6.10 & Flower blooming $\geq 10 \%$ \\
\hline 1.11 & Eleven rosette leaves $\geq 1 \mathrm{~mm}$ & 6.30 & Flower blooming $\geq 30 \%$ \\
\hline 1.12 & Twelve rosette leaves $\geq 1 \mathrm{~mm}$ & 6.50 & Flower blooming $\geq 50 \%$ \\
\hline 1.13 & Thirteen rosette leaves $\geq 1 \mathrm{~mm}$ & 6.90 & Flower blooming $\geq 100 \%$ \\
\hline 1.14 & Fourteen rosette leaves $\geq 1 \mathrm{~mm}$ & \multicolumn{2}{|r|}{ Ripening of Siliques } \\
\hline & & 8.00 & Shattering of the first silique \\
\hline & & \multicolumn{2}{|r|}{ Senescence of Plants } \\
\hline & & 9.70 & Senescence of the plants completed \\
\hline
\end{tabular}




\section{Results}

Analysis of A. thaliana wild type (Col-0) and mutant lines (as3-3, as2-6, al1-5 and al4-3) presented here provides insights into differences in plant phenotype resulting from reduced arginine cycling. The role of arginine synthesis during plant growth and development was analyzed using amiRNAdirected gene silencing. Two important genes in the arginine biosynthesis pathway, argininosuccinate synthase $(A S)$ and argininosuccinate lyase $(A L)$ were chosen for silencing due to their importance in arginine biosynthesis [11]. Homozygous mutant lines were tested for gene silencing efficiencies of the amiRNA inserts using qRT-PCR. Gene expression of $A S$ and $A L$ in wild type plants was compared with mutant lines (as3-3, as2-6, all-5 and al4-3) and the mutants with more than $50 \%$ decrease in the expression were selected for further analysis. In case of $A S$ mutant lines, as 3-3 and as 2-6 showed almost $60 \%$ decrease in gene expression. Whereas two $A L$ mutants all-5 and al4-3 showed more than 50\% decrease in gene expression (Fig. 2A).

To elucidate the actual effect of the mutation on arginine biosynthesis pathway, amino acid profiling of the mutant lines (as 2- 6 and al4-3) was performed using Waters Ultra High-Performance liquid chromatography $\left(\mathrm{UPLC}^{\mathrm{TM}}\right.$ ) system [19]. Arginine content of 20-day-old as2-6 and al4-3 lines was reduced to $46 \%$ and $54 \%$, respectively, as compared to the wild type plants. However, in 30-day-old plants arginine levels tend to increase and in as2-6 and al4-3 lines the arginine content was $50 \%$ and $57 \%$ respectively, compared to the wild type plants (Fig. 2B).
Growth stages of $A$. thaliana analyzed here (Table 2 \& 3; Fig. 1) are adopted from $\mathrm{BBCH}$ scale $[20,21]$ and span the whole life cycle of $A$. thaliana ranging from imbibition of seed to the ripening of siliques and senescence of the plants. We recorded the time in days required for each stage to complete in the wild type and mutant lines (as3-3, as2-6, al1-5 and al4-3) under standard environmental conditions of $16 \mathrm{~h}$ light $/ 8 \mathrm{~h}$ dark and at $25^{\circ} \mathrm{C}$ in a growth chamber. We collected growth data in two phases as mentioned in material and method section. In the first experiment data was collected from seed imbibition to early developmental stages. In this plate-based experiment none of the mutant lines showed any significant difference from the wild type plants (Fig. 3A). After the completion of the plate-based experiment, plants were grown in pots for the second phase of the study. Second phase spans the stages from leaf development to the maturation of siliques and senescence of the plants. In this phase, growth stages 1.02 to 1.14 did not show any significant difference between wild type and mutant plants (Fig. 3B). However, rosette growth in mutant plants took more time to complete as compared to the wild type plants (Fig. 3C \& 4A). There was also a difference in flowering response between wild type and mutant plants. In mutant plants inflorescence emergence was late and first flower bud appeared almost 2-3 days later than in wild type plants (Fig. 3C \& 4B). Flower blooming started also late in the mutant plants as compared to wild type, but later flowering stages synchronized again in both mutants and wild type plants (Fig. 3C \& 4C). 

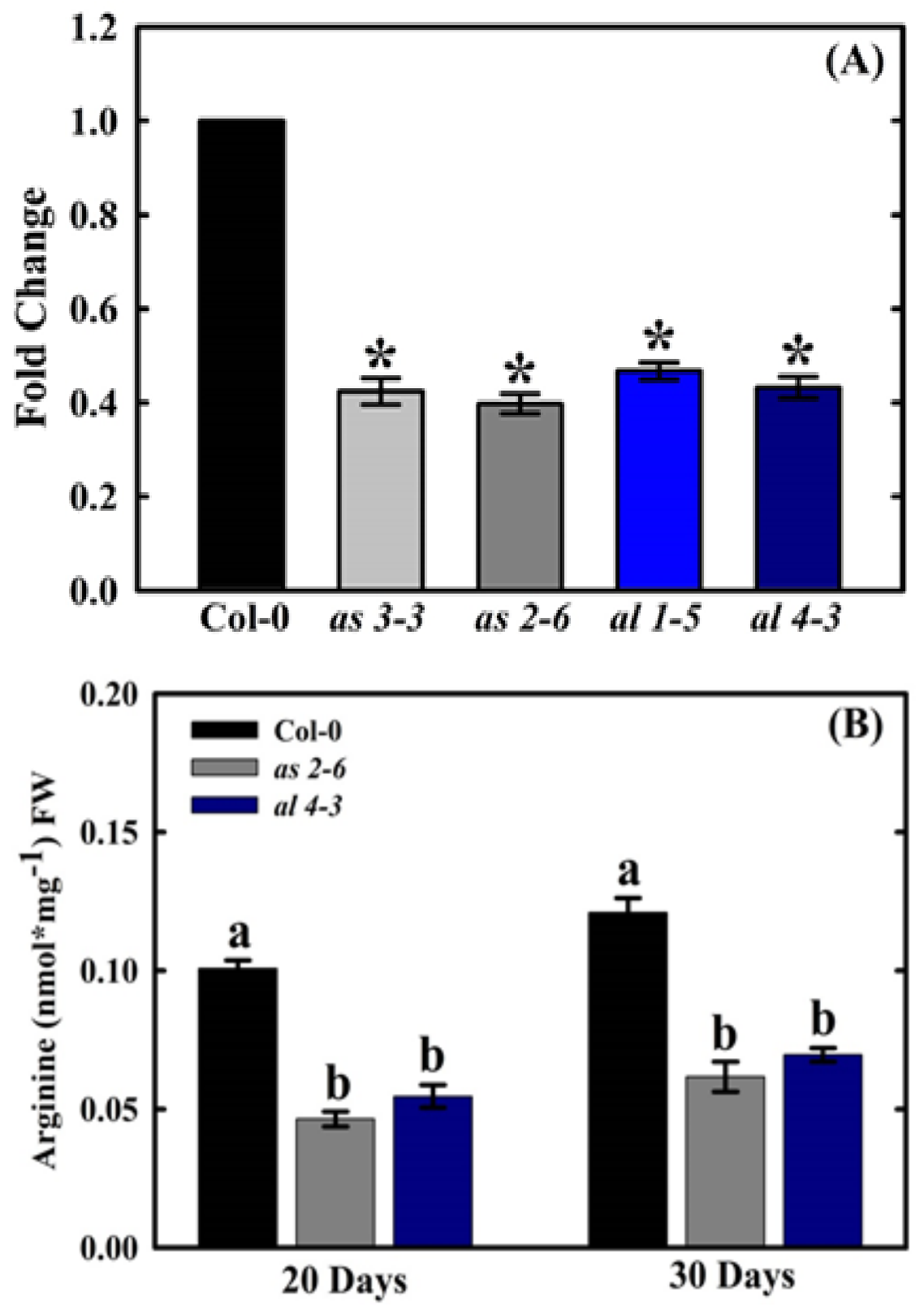

Figure 2. (A) Argininosuccinate synthase $(A S)$ and argininosuccinate lyase $(A L)$ gene expression in amiRNA-based $A$. thaliana mutant plant lines (as3-3, as2-6, al1-5 and al4-3) quantified by qRT-PCR. Mean values are shown in chart \pm SE, Data was collected from three biological replicates and each sample was run in three technical replicates. * represents significant downregulation of genes compared to wild type $A$. thaliana (Col-0) plants (t-test, p < 0.05). (B) Arginine contents in $A$. thaliana wild type and amiRNA-based mutant plant lines (as2-6 and al4-3) were quantified by using UPLC ${ }^{\text {TM }}$. Mean values are shown in chart $\pm S E, n=5$ (Biological replicates). Significant difference within a group is shown by different letters (One-way ANOVA, LSD, $p<0.05$ ) 

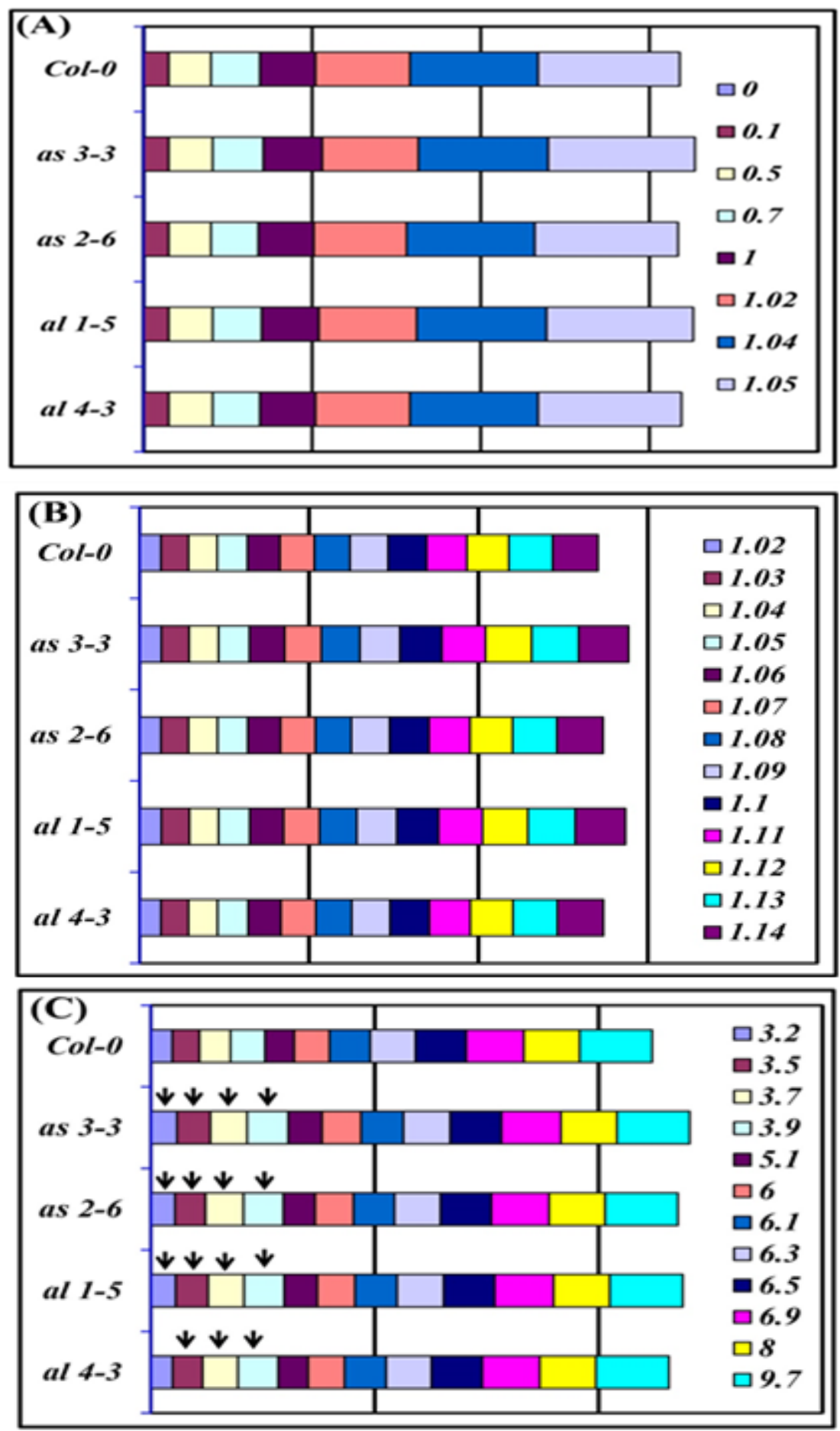

Figure 3. Phenotypic analysis of wild type $A$. thaliana (Col-0) and amiRNA-based mutant lines (as3-3, as 2-6, al1-5 and al4-3). (A) Plate-based experiment results; growth stages 0 to 1.05 (B) Soil-based experiment results, growth stages 1.02 to 1.14 (C) Soil-based experiment results, growth stages 3.2 to 9.7. Boxes represent the chronological events among successive growth stages. Data shown here is mean of five biological replicates. Arrowheads represent a significant difference from wild type plants 

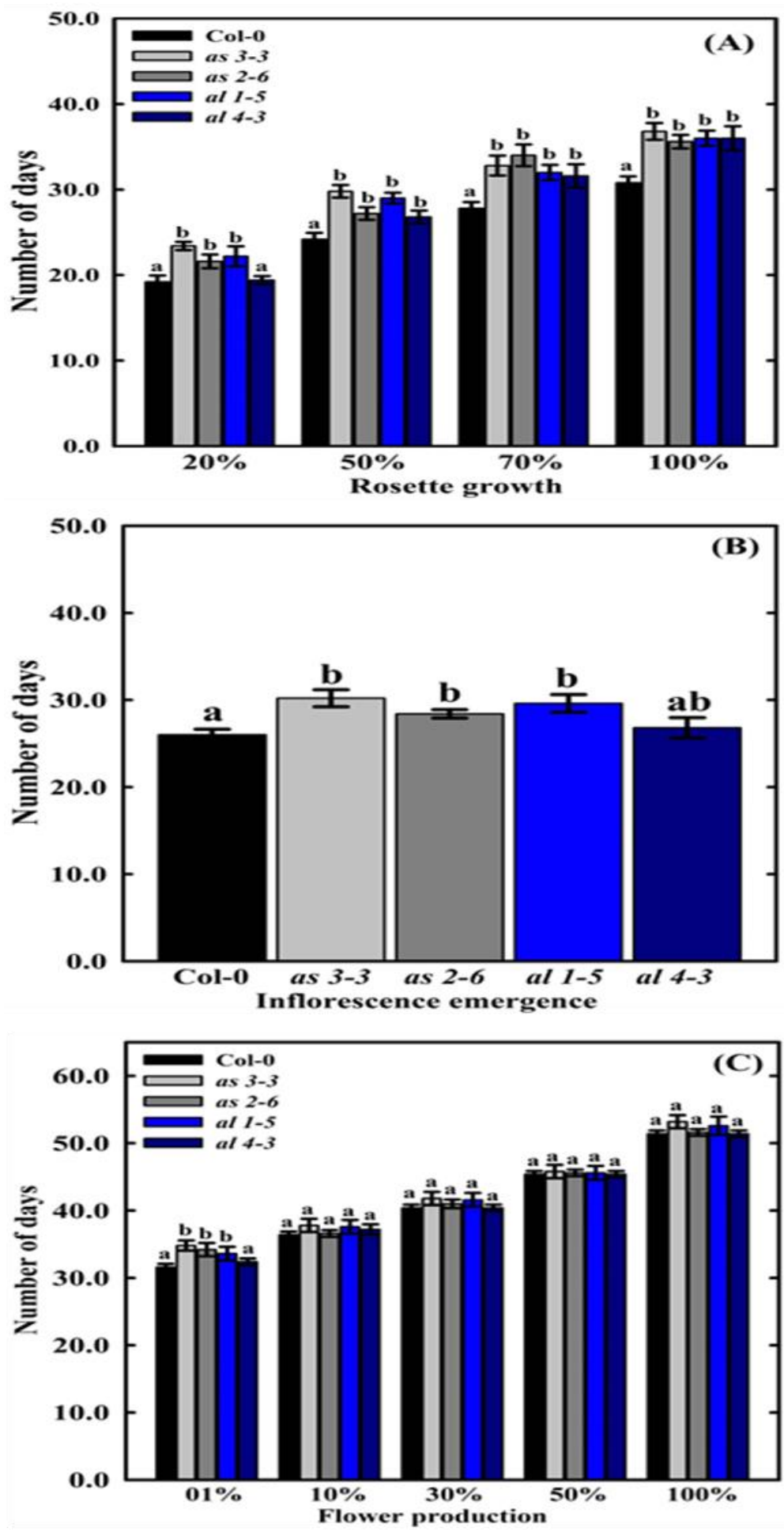

Figure 4. Growth stage data from wild type $A$. thaliana (Col-0) and amiRNA-based mutant lines (as3-3, as2-6, al1-5 and al4-3). (A) Number of days taken for rosette growth from $20 \%$ to $100 \%$ of full size. (B) Number of days taken for inflorescence emergence i.e. first flower bud visible. (C) Number of days taken for flower production $1 \%$ (first flower bloom) to $100 \%$ (no flower bud visible) 


\section{Discussion}

This study was performed to target phenotypic implications of silencing two genes coding for argininosuccinate synthase (AS) and argininosuccinate lyase (AL) in arginine metabolic pathway. Main aim of the study was to unravel potential differences in phenotype between wild type and argininedeficient mutant plants. Since AS was already found to regulate the synthesis of arginine in urea cycle [22], these genes were selected as potential candidate to reduce the synthesis of arginine in A. thaliana. Silencing of these two genes resulted in a significant decrease in arginine production. Arginine is not only essential amino acid in plants but also serve as precursor for the synthesis of many physiologically important metabolites [23, 24]. Arginine is synthesized in plants from ornithine during so-called urea cycle $[9,25]$, which is also referred to as arginine metabolic pathway. In this pathway, citrulline is catabolized by AS and AL to arginine [11], which can then be again catabolized to ornithine by the action of arginase enzyme in the final step of urea cycle [26]. In most of the plant species arginine is the major amino acid in seed proteins and it plays important role in the nutritional demand of the developing seedling [12]. Arginine also serves as major nitrogen storage form in roots and underground storage organs of plants [13, 27]. Transport of arginine within plants is mostly done via vascular tissue and it depends upon AAP amino acid transporters. Especially AAP5 family has a high rate of arginine transport in plants [28, 29]. External application of arginine is reported to increase the biomass and shoot length in plants [30].

Growth and development of plants is controlled by multiple genetic and environmental factors [31]. Most of the methods for study the growth and development of a plant depend upon the quantification of plant phenotype. In this study we used growth stage-based analysis of plants [20] to determine the effect of silencing of two genes, argininosuccinate synthase $(A S)$ and argininosuccinate lyase $(A L)$. Our findings suggest that limiting the biosynthesis of arginine interferes with normal growth and development of rosette and delays flowering in A. thaliana. This can be a direct effect of silencing the $A S$ and $A L$ as both genes are involved in the initial stages of rosette growth and development as well as in the flowering response of $A$. thaliana [32], or due to the deficiency of arginine in urea cycle of the plant. Arginine serves as precursor for many metabolites in A. thaliana, which are involved in vital physiological processes [10]. Catabolism of arginine starts with its conversion into ornithine and urea. This reaction in $A$. thaliana is catabolized by an arginase enzyme coded by two genes $A R G A H 1$ and $A R G A H 2$. Arginase has a well-established role in the flow of nitrogen stored in arginine during many developmental processes of plants [10]. However, mutation in these genes did not translate to any developmental defects [10]. Arginine is also an important precursor for proline biosynthesis. Proline plays an important role as a compatible osmolyte against many stress responses especially during water stress [33]. However, proline accumulation is also reported in different plant organs during non-stress conditions. Reproductive structures accumulate a large amount of proline during growth and development [34]. We found delayed flowering in our mutants which can be a result of decrease proline accumulation due to less availability of arginine as a precursor. This is in line with reports showing delayed flowering response in proline-deficient $A$. thaliana mutants $[35,36]$. Silencing of genes coding for enzymes converting the arginine into proline also results in late flowering 
transition and retarded growth of $A$. thaliana plants [36, 37]. Polyamines are important molecules in regulation of plant metabolism and play a central role in cell signaling and many metabolic pathways [38]. Polyamines are a class of growth regulators found in plants [39]. Polyamine biosynthesis requires arginine as a precursor molecule $[40,41]$. Their deficiency can affect many developmental processes in A. thaliana [42]. Exogenous application of spermidine greatly enhanced the flowering response of plants which normally poorly flower [43]. Early spike in polyamine levels leads to the earlier bolting in plants [44]. Accordingly, developmental changes in arginine-deficient mutants can be an indirect result of decreased polyamine production.

\section{Conclusion}

Studying the relationship between important metabolites is a key to understand biological and developmental processes in plants. In this study, we present the change in phenotype of arginine-deficient mutants in comparison to wild type $A$. thaliana plants. The knowledge on nitrogen remobilization can help in improving the crop plants for better growth and yield.

\section{Authors' contributions}

Conceived and designed the experiments: $\mathrm{S}$ Anwar, MA Ali, E Inselsbacher \& K Wieczorek, Performed the experiments: S Anwar, MA Ali \& E Inselsbacher, Analyzed the data: S Anwar, Contributed materials/ analysis/ tools: $\mathrm{K}$ Wieczorek, Wrote the paper: S Anwar \& K Wieczorek.

\section{Acknowledgment}

We acknowledge the Higher Education Commission (HEC) of Pakistan for funding the work. Help and support from Prof. Florian Grundler, Prof. Holger Bohlmann and Dr. Julia Hofmann (BOKU Wien) is also acknowledged.

\section{References}

1. Meinke DW, Cherry JM, Dean C, Rounsley SD \& Koornneef M (1998). Arabidopsis thaliana: A Model Plant for
Genome Analysis. Science 282(5389): 662-682.

2. Wienkoop S, Baginsky S \& Weckwerth W (2010). Arabidopsis thaliana as a model organism for plant proteome research. J Proteomics 73(11): 22392248.

3. Krysan PJ, Young JC \& Sussman MR (1999). T-DNA as an insertional mutagen in Arabidopsis. Plant Cell 11(12): 22832290.

4. Alonso JM, Stepanova AN, Leisse TJ, Kim CJ, Chen H, Shinn P, Stevenson DK, Zimmerman J, Barajas P, Cheuk R, Gadrinab C, Heller C, Jeske A, Koesema E, Meyers CC, Parker H, Prednis L, Ansari Y, Choy N, Deen H, Geralt M, Hazari N, Hom E, Karnes M, Mulholland C, Ndubaku R, Schmidt I, Guzman P, Aguilar-Henonin L, Schmid M, Weigel D, Carter DE, Marchand T, Risseeuw E, Brogden D, Zeko A, Crosby WL, Berry CC, Ecker JR (2003). Genome-wide insertional mutagenesis of Arabidopsis thaliana. Science 301(5633): 653-657.

5. Chuang CF \& Meyerowitz EM (2000). Specific and heritable genetic interference by double-stranded RNA in Arabidopsis thaliana. PNAS 97(9): 49854990.

6. Schwab R, Ossowski S, Riester M, Warthmann N \& Weigel D (2006). Highly specific gene silencing by artificial microRNAs in Arabidopsis. Plant Cell 18(5): 1121-1133.

7. Bouché N \& Bouchez D (2001). Arabidopsis gene knockout: phenotypes wanted. Curr Opin Plant Biol 4(2): 111117.

8. Wu GY \& Morris SM (1998). Arginine metabolism: nitric oxide and beyond. Biochem J 336(Pt-1): 1-17.

9. Micallef BJ \& Shelp BJ (1989). Arginine Metabolism In Developing Soybean Cotyledons II. Biosynthesis. Plant Physiol 90(2): 631-634.

10. Winter G, Todd CD, Trovato M, Forlani G \& Funck D (2015). Physiological 
implications of arginine metabolism in plants. Front Plant Sci 6:534.

11. Slocum RD (2005). Genes, enzymes and regulation of arginine biosynthesis in plants. Plant Physiol Biochem 43(8): 729745.

12. King JE \& Gifford DJ (1997). Amino Acid Utilization in Seeds of Loblolly Pine during Germination and Early Seedling Growth (I. Arginine and Arginase Activity). Plant Physiol 113(4): 1125-1135.

13. Bausenwein U, Millard P, Thornton B \& Raven JA (2001). Seasonal nitrogen storage and remobilization in the forb Rumex acetosa. Funct Ecol 15(3): 370377.

14. Anwar S, Ali MA, Abbas A \& Wieczorek K (2019). Arabidopsis Argininosuccinate Lyase and Argininosuccinate Synthase are important for resistance against Pseudomonas syringae. Adv Life Sci 7(1): 20-26.

15. Murashige $T$ \& Skoog F (1962). A Revised Medium for Rapid Growth and Bio Assays with Tobacco Tissue Cultures. Physiol Plant 15(3): 473-497.

16. Szakasits D, Siddique $S \&$ Bohlmann $H$ (2007). An improved pPZP vector for Agrobacterium-mediated plant transformation. Plant Mol Biol Rep 25: 115-120.

17. Clough SJ \& Bent AF (1998). Floral dip: a simplified method for Agrobacteriummediated transformation of Arabidopsis thaliana. Plant J 16(6): 735-743.

18. Livak KJ \& Schmittgen TD (2001). Analysis of Relative Gene Expression Data Using Real-Time Quantitative PCR and the 2(-Delta Delta $\mathrm{C}(\mathrm{T}))$ Method. Methods 25(4): 402-408.

19. Inselsbacher E, Öhlund J, Jämtgård $S$, Huss-Danell K \& Näsholm T (2011). The potential of microdialysis to monitor organic and inorganic nitrogen compounds in soil. Soil Biol and Biochem 43(6): 1321-1332.

20. Boyes DC, Zayed AM, Ascenzi R, McCaskill AJ, Hoffman NE, Davis KR \&
Görlach J (2001). Growth stage-based phenotypic analysis of Arabidopsis: a model for high throughput functional genomics in plants. Plant Cell 13(7): 1499-1510.

21. Lancashire PD, Bleiholder $\mathrm{H}$, Boom TVD, Langelüddeke P, Stauss R, Weber E \& Witzenberger A (1991). A uniform decimal code for growth stages of crops and weeds. Ann Appl Biol 119(3): 561601.

22. Haines RJ, Pendleton LC \& Eichler DC (2011). Argininosuccinate synthase: at the center of arginine metabolism. Int $J$ Biochem Mol Biol 2(1): 8-23.

23. Facchini PJ (2001). ALKALOID BIOSYNTHESIS IN PLANTS: Biochemistry, Cell Biology, Molecular Regulation, and Metabolic Engineering Applications. Annu Rev Plant Physiol Plant Mol Biol 52:29-66.

24. Slocum RD, Kaur-Sawhney R \& Galston AW (1984). The physiology and biochemistry of polyamines in plants. Arch Biochem Biophys 235(2): 283-303.

25. Shargool D, Jain JC \& McKay G (1988). Ornithine biosynthesis, and arginine biosynthesis and degradation in plant cells. Phytochemistry 27(6): 1571-1574.

26. Goldraij A \& Polacco JC (2000). Arginine degradation by arginase in mitochondria of soybean seedling cotyledons. Planta 210(4): 652-658.

27. Rennenberg $\mathrm{H}$, Wildhagen $\mathrm{H} \&$ Ehlting $\mathrm{B}$ (2010). Nitrogen nutrition of poplar trees. Plant Biol (Stuttg) 12(2): 275-291.

28. Tegeder M (2014). Transporters involved in source to sink partitioning of amino acids and ureides: opportunities for crop improvement. J Exp Bot 65(7): 18651878.

29. Svennerstam H, Jämtgård $S$, Ahmad I, Huss-Danell K, Näsholm T \& Ganeteg U (2011). Transporters in Arabidopsis roots mediating uptake of amino acids at naturally occurring concentrations. New Phytol 191(2): 459-467.

30. Nejadalimoradi H, Nasibi F, Kalantari KM \& Zanganeh R (2014). Effect of seed 
priming with L-arginine and sodium nitroprusside on some physiological parameters and antioxidant enzymes of sunflower plants exposed to salt stress. Agric Commun 2(1): 23-30.

31. Taiz L \& Zeiger E (2003). Growth and Development In: Sunderland Sinauer Associates Incorporated. Plant physiology third Edition., Sunderland. Annals of Botany pp339-374.

32. Schmid M, Davison TS, Henz SR, Pape UJ, Demar M, Vingron M, Schölkopf B, Weigel D \& Lohmann JU (2005). A gene expression map of Arabidopsis thaliana development. Nat Genet 37(5): 501-506.

33. Lehmann S, Funck D, Szabados L \& Rentsch D (2010). Proline metabolism and transport in plant development. Amino Acids 39(4): 949-962.

34. Mattioli R, Costantino $P$ \& Trovato $M$ (2009). Proline accumulation in plants Not only stress. Plant Signal Behav 4(11): 1016-1018.

35. Strizhov N, Ábrahám E, Ökrész L, Blickling S, Zilberstein A, Schell J, Koncz C \& Szabados L (1997). Differential expression of two P5CS genes controlling proline accumulation during salt-stress requires $\mathrm{ABA}$ and is regulated by $\mathrm{ABA} 1, \mathrm{ABI} 1$ and $\mathrm{AXR} 2$ in Arabidopsis. Plant J 12(3) 557-569.

36. Mattioli R, Marchese D, D'Angeli S, Altamura MM, Costantino P \& Trovato M (2008). Modulation of intracellular proline levels affects flowering time and inflorescence architecture in Arabidopsis. Plant Mol Biol 66(3): 277-288.

37. Nanjo $T$, Kobayashi M, Yoshiba $Y$, Sanada Y, Wada K, Tsukaya H, Kakubari Y, Yamaguchi-Shinozaki K \& Shinozaki K (1999). Biological functions of proline in morphogenesis and osmotolerance revealed in antisense transgenic Arabidopsis thaliana. Plant J 18(2): 185193.

38. Pathak MR, Teixeira da Silva JA \& Wani SH (2014). Polyamines in response to abiotic stress tolerance through transgenic approaches. GM Crops Food 5(2): 87-96.

39. Xu L, Xing ST, Sun XZ, Guo JE \& Xu DH (2014). Effects of Polyamines on Hormones Contents and the Relationship with the Flower Bud Differentiation in Chrysanthemum. Zhiwu Shengli Xuebao/Plant Physiol J 50(8): 11951202.

40. Bagni N \& Tassoni A (2001). Biosynthesis, oxidation and conjugation of aliphatic polyamines in higher plants. Amino Acids 20(3): 301-317.

41. Illingworth $\mathrm{C}$, Mayer $\mathrm{MJ}$, Elliott $\mathrm{K}$, Hanfrey C, Walton NJ \& Michael AJ (2003). The diverse bacterial origins of the Arabidopsis polyamine biosynthetic pathway. FEBS Lett 549(1-3): 26-30.

42. Chen D, Shao Q, Yin L, Younis A \& Zheng B (2019). Polyamine Function in Plants: Metabolism, Regulation on Development, and Roles in Abiotic Stress Responses. Front Plant Sci 9:1945.

43. Applewhite PB, Kaur-Sawhney R \& Galston AW (2000). A role for spermidine in the bolting and flowering of Arabidopsis. Physiol Plant 108(3): 314-320.

44. Ai Y, Chen G \& Zhou Y (2011). The study on polyamine metabolism in leaves during flower formation in the earlymaturing mutant of Brassica napus L. Chin Agric Sci Bull 27: 101-105. 